\title{
Pemberdayaan Masyarakat Tentang Pengelolaan Sampah dengan Teknik Komposter dan Pemanfaatan Pekarangan Sekolah untuk Tanaman Sayur Sebagai Gerakan Masyarakat Hidup Sehat
}

\author{
Mohammad Rachman Waluyo ${ }^{1 *}$, Fajar Rahayu ${ }^{2}$, Akalily Mardiyah ${ }^{3}$ \\ 1,2,3 Universitas Pembangunan Nasional "Veteran" Jakarta
}

\author{
A R T I C L E I N F O \\ Article history: \\ Received 20 May 2019 \\ Received in revised form \\ 10 June 2019 \\ Accepted 30 July 2019 \\ Available online 30 August \\ 2019 \\ Kata Kunci: \\ GERMAS, pekarangan \\ sekolah, sampah, \\ Komposter \\ Keywords: \\ GERMAS, school yard, \\ garbage, Composter
}

\begin{abstract}
A B S T R A K
Terkait dengan kesehatan masyarakat, Kementrian Kesehatan Republik Indonesia mencanangkan sebuah gerakan yang memasyarakatkan budaya hidup sehat serta meninggalkan kebiasaan dan perilaku masyarakat yang kurang sehat. Namun, promosi kesehatan dan pencegahan penyakit yang telah ada kurang dapat berkontribusi dalam meningkatkan derajat kesehatan masyarakat. Dengan dasar inilah kami Fakultas Teknik UPNVJ bekerjasama dengan SD Tunas Mandiri bermaksud mengadakan pemberdayaan pemanfaatan pekarangan sekolah untuk tanaman sayur dan buah, menanamkan kesadaran peduli sampah dengan Teknik komposter guna membentuk kesadaran cinta lingkungan. Diharapkan dengan adanya pemberdayaan masyarakat berupa GERMAS, dapat meningkatkan wawasan akan lingkungan bagi siswa, orang tua dan komite SD Tunas Mandiri akan mengerti cara pengelolaan sampah berbasiskan komposter, meningkatkan kemandirian dan perekenomian masyarakat, dan yang paling utama adalah meningkatkan kualitas kesehatan dan kesadaran siswa sejak dini. Target luaran dari program
\end{abstract} ini berupa produk pengolahan sampah dengan komposter dan pemanfaatan lahan SD Tunas Mandiri untuk dijadikan wahana pemberlajaran untuk anak - anak budidaya di pekarangan sekolah agar bisa dijadikan pembelajaran buat siswa dan bisa dikelola sekolah.

A B S T R A C T

Related to public health, Kementrian Kesehatan Republik Indonesia launched a movement that promotes a culture of healthy living and abandons unhealthy habits and behavior of the people. However, health promotion and prevention of existing diseases are less able to contribute in improving the degree of public health. With this basis, our UPNVJ Faculty of Engineering in collaboration with SD Tunas Mandiri intends to empower the use of the school yard for vegetable and fruit plants, instill awareness of waste care with composter technique to form awareness of environmental love. It is hoped that the community empowerment in the form of GERMAS can increase environmental insights for students, parents and the SD Tunas Mandiri committee, will understand how to manage composter-based waste management, increase community independence and economy, and most importantly, improve the quality of students' health and awareness early on . The output target of this program is in the form of waste processing products with composter and land use of SD Tunas Mandiri to be used as a learning vehicle for children cultivating in the school yard so that it can be used as learning for students and can be managed by the school. of the Wonolopo Village community and create 2 new 'UMKM" , namely "UMKM Sabun Rempah" and "UMKM Pupuk Organik Cair" made from herbal waste.

Copyright (C) Universitas Pendidikan Ganesha. All rights reserved.

Corresponding author.

E-mail addresses: aanvicenzo@gmail.com (Mohammad Rachman Waluyo) 


\section{Pendahuluan}

Permasalahan lingkungan merupakan penurunan daya dukung lingkungan sebagai akibat rendahnya kesadaran masyarakat terhadap pentingnya pengelolaan lingkungan. Hal ini disebabkan oleh beberapa faktor, antara lain: perubahan fungsi dan tatanan lingkungan, penurunan daya dukung dan mutu lingkungan, tidak adanya keterpaduan pengelolaan sumber daya manusia, alam, dan buatan dalam pengelolaan lingkungan antar berbagai pihak, kurang optimalnya pemanfaatan ruang kota, serta pencemaran lingkungan yang dihasilkan oleh adanya sampah. Sampah merupakan salah satu permasalahan lingkungan yang memerlukan penanganan serius. Berdasarkan Undang-Undang No. 18 Tahun 2008, sampah adalah sisa kegiatan sehari-hari manusia dan atau proses alam yang berbentuk padat. Secara umum sampah dibedakan menjadi tiga, yaitu sampah organik/basah, sampah anorganik/kering, dan sampah berbahaya. Seiring dengan meningkatnya jumlah penduduk di suatu wilayah maka juga mengakibatkan bertambahnya volume sampah. Pola konsumsi masyarakat ikut memberi kontribusi dalam peningkatan volume sampah yang semakin beragam jenisnya. Sampah rumah tangga merupakan salah satu sumber sampah yang cukup besar peranannya dalam peningkatan volume sampah di suatu lingkungan. Oleh karena itu untuk mengatasi masalah pencemaran tersebut diperlukan penanganan dan pengendalian terhadap sampah. Penanganan dan pengendalian akan menjadi semakin kompleks dan rumit dengan semakin kompleksnya jenis maupun kompisisi dari sampah sejalan dengan majunya kebudayaan. Masalah yang sering muncul dalam penanganan sampah adalah masalah biaya operasional yang tinggi dan sulitnya ruang yang pantas untuk pembuangan.

Pengelolaan sampah masih kurang mendapat penanganan yang optimal dari berbagai pihak, baik dari masyarakat setempat maupun pemerintah daerah. Penanganan yang kurang optimal akan menimbulkan berbagai permasalahan lingkungan, seperti timbulnya banjir, timbulnya penyakit, sanitasi lingkungan memburuk, turunnya kandungan organik lahan pertanian, dan mempercepat terjadinya pemanasan global. Oleh karena itu diperlukan adanya komitmen bersama dalam pengelolaan sampah sehingga tidak menimbulkan berbagai permasalahan lingkungan. Peran masyarakat dalam pengelolaan sampah diperlukan tidak hanya sebatas dalam membuang sampah di tempat yang seharusnya, namun diharapkan termasuk juga pengolahan sampah yang memberikan manfaat kembali bagi masyarakat itu sendiri. Dalam hal ini sebagai salah satu bentuk tanggung jawab dosen dalam melaksanakan tridarma perguruan tinggi maka perlu diadakan pengabdian pada masyarakat berupa pelatihan pengelolaan sampah rumah tangga dengan metode sederhana, yaitu composting dan pemanfaatan lahan yang tidak produktif sebagai sarana pembelajaran bercocok tanam untuk Siswa SD Tunas Mandiri guna menciptakan mindset cinta akan lingkungan. Dengan adanya pelatihan ini diharapkan sampah organik selanjutnya dapat dijadikan pupuk kompos yang dapat menyuburkan tanaman, bahkan dapat dijual kepada konsumen yang membutuhkan. Perempuan memiliki peran penting dalam pengelolaan sampah rumah tangga, terkait salah satu perannya sebagai ibu rumah tangga.

\section{Metode}

Metode Berdasarkan masalah di atas yang belum terpecahkan yaitu kesadaran dan kebiasaan pengelolaan sampah berbasiskan Teknik komposter. Selain itu, program ini diharapkan dapat menjaga keberlangsungan solusi tersebut di atas, tentunya dengan cara alih teknologi ke masyarakat mitra. Agar program pengabdian tersebut terjamin terwujud dan terjamin pelaksanaannya maka dibutuhkan langkah langkah yang sistematis dan terukur. Berikut langkah-langkahnya: 1. Memetakan landscape mitra sasaran menggunakan map.google, 2. Tim UPN datang untuk melihat permasalahan pada mitra di SD Tunas Mandiri. 3. Tim UPN melakukan proses perencanaan meliputi identifikasi kebutuhan, identifikasi potensi dan kelemahan yang ada, menentukan jalan keluar dan kegiatan yang akan dilakukan, dan membuat pengorganisasian kegiatan. 4. Tim UPN melakukan pelatihan salah satunya pemanfaatan pekarangan sekolah untuk tanaman sayur dan buah, mengurangi dan menamamkan kesadaran peduli sampah serta membentuk kesadaran cinta lingkungan dan cinta akan diri sendiri. Pada tahap ini dilakukan pembekalan awal dan disesuaikan dengan hasil mapping yang telah dilakukan. 5. Tim UPN dan warga SD Tunas Mandiri sama-sama bekerjasama untuk menciptakan lingkungan yang sehat tanpa menggunakan smart phones dan lebih peduli terhadap sampah.

\section{Hasil dan pembahasan}

Dari permasalahan teknik pengelolaan sampah diatas, teknologi yang umum digunakan dalam proses lanjutan setelah sampah ditimbun di TPA salah satunya adalah komposting. Komposting adalah teknik menghasilkan kompos yang digunakan sebagai pupuk maupun penguat struktur tanah. 
Komposting digunakan untuk mempecepat proses degradasi bahan organik dengan bantuan mikroba. Secara alami komposting berlangsung cukup lama, biasanya 3 - 4 bulan. Untuk mempercepat komposting, diperlukan adanya perlakuan khusus, seperti penggunaan bioreaktor khusus, campuran bahan organik, dan sumber mikroba pengurai. Komposting dapat dilakukan dalam skala besar maupun rumah tangga. Komposting skala rumah tangga menggunakan drum khusus yang didesain untuk mempermudah dan mempercepat proses komposting. Keuntungan komposting skala rumah tangga, yaitu: a. Tidak membutuhkan lahan yang luas. b. Komposting tidak menghasilkan bau yang menganggu. c. Kontrol mudah dilakukan, sehingga kualitas kompos lebih baik. Bahan dan alat yang dibutuhkan untuk komposting adalah reaktor kompos, yaitu reaktor yang dapat digunakan bermacam-macam tergantung lokasi, kebutuhan, dan kapasitas sampah. Reaktor tersebut dapat berupa bak terbuka, lubang pada tanah, atau reaktor khusus berbentuk drum. Bahan organik dapat berupa dedaunan, sampah dapur seperti sayuran, nasi, dan sebagainya. Dalam komposting perlu adanya upaya menghindari memasukkan cangkang telur, daging, dan tulang karena akan memperlambat proses pengomposan dan menimbulkan bau busuk. Suplai udara untuk proses degradasi berlangsung secara aerob, sehingga membutuhkan aerasi yang baik. Semakin baik aerasi maka proses degradasi akan semakin cepat. Air untuk pertumbuhan mikroba juga membutuhkan kelembaban yang cukup. Oleh karena itu, kompos harus sering disiram agar tetap lembab. Sumber bakteri/jamur pengurai secara sederhana, yaitu mikroba pengurai banyak terdapat di kotoran ternak. Selain itu, mikroba dapat diperoleh dari biakan khusus yang disebut biokatalis atau bioaktifator. Komposter disajikan dalam gambar 1 di bawah ini

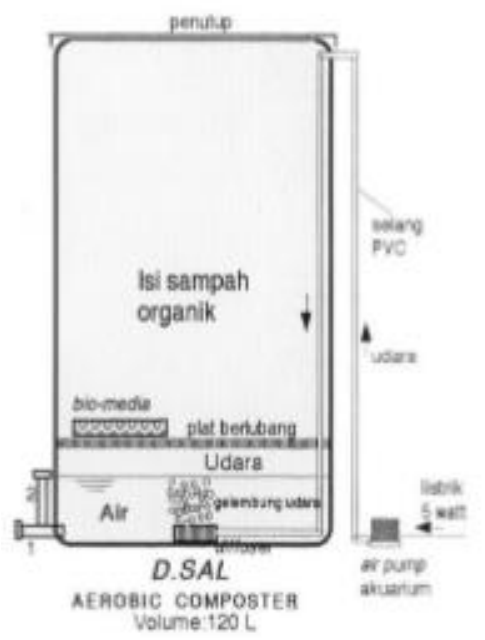

Gambar 1. Komposter dengan aerator

Langkah-langkah menggunakan Tong sampah komposter:

1. Pisahkan sampah organik dan non oirganik.

2. Sampah organik dibuang kedalam tong sampah composter merah-putih.

3. Semprotkan bioaktifator (yang sudah dipaketkan) masukan kedalam spray atau botol yang sudah diberikan lubang kecil-kecil.

4. Taburkan pasir, tanah, atau serbuk gergaji utk mencegah belatung $2-3 \mathrm{~cm}$.

5. Tutup rapat sampah, bila sudah tidak membuang sampah kembali agar terfermentasi sempurna.

6. Sampah bisa diisi berulang kali selama belum memasuki masa maksimal (tersedia berbagai ukuran)

7. Selama satu minggu dari pemakaian akan mengeluarkan poc (pupuk organik cair) dapat terlihat dari selang pada bagian bawah guna menampung poc.

8. Panen POC 2 hari sekali sampai warna kehitaman.

9. Ketika memasuki masa maksimal (sampah sudah padat) tutup 2-3 minggu tong dan jangan diiisi sampah kembali

10. Buka tutup tong utk menghasilkan kompos. selanjutnya dipakai berulang-ulang seperti semula.

11. Untuk tong yang ukuran $12 \mathrm{bln}$ atau 120 liter dan $24 \mathrm{bln} 200$ liter tersedia pintu samping. hanya 6 bulan kompos dapat dipanen tanpa menunggu waktu lama. 


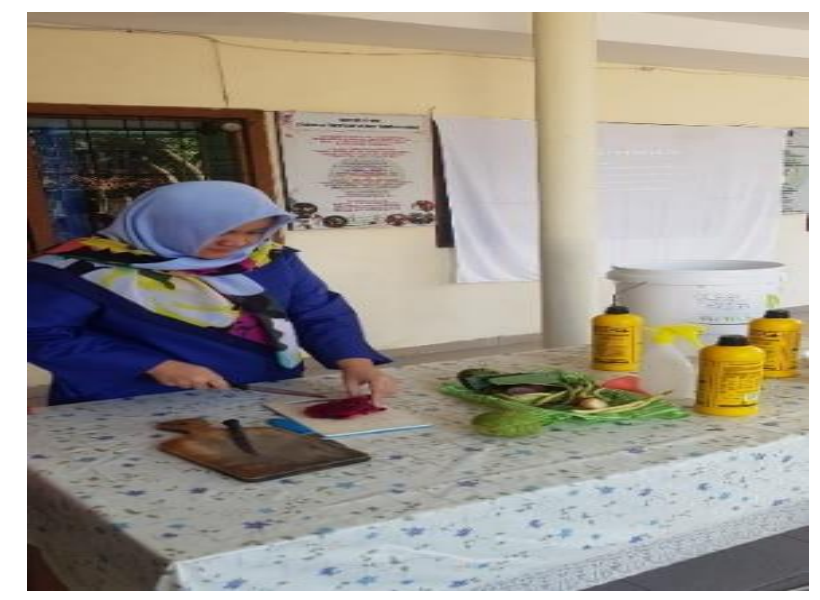

Gambar 2. Pemilahan Bahan Yang Akan Yang Dimasukan Di Proses Komposter
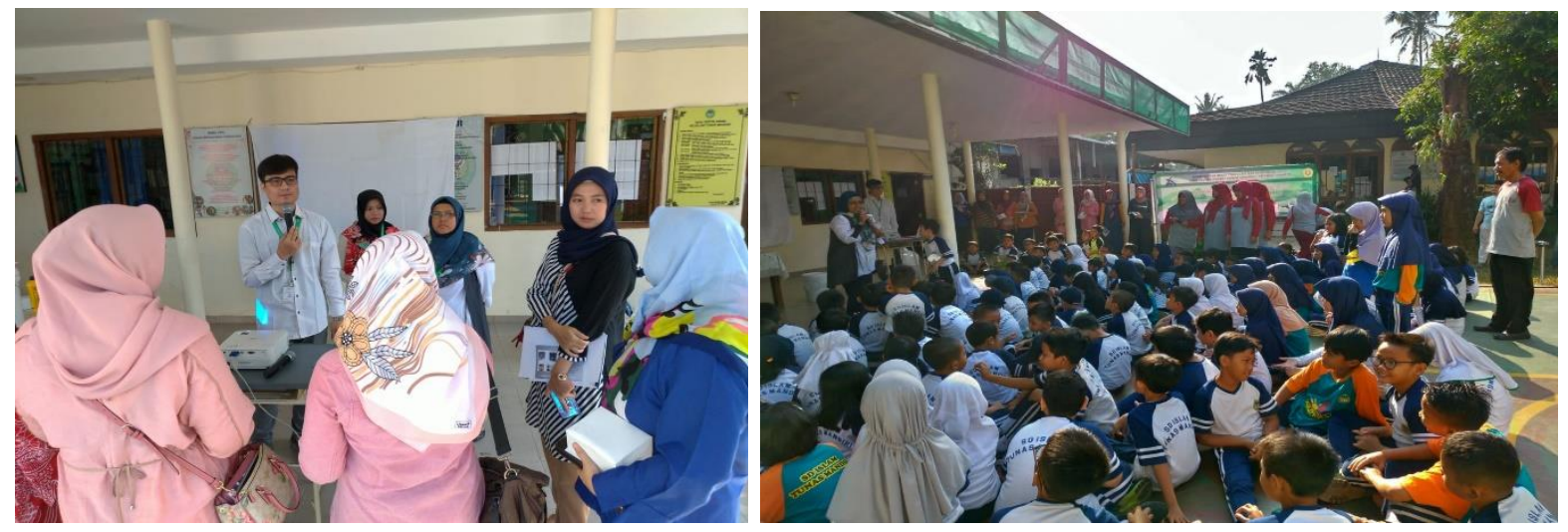

Gambar 3. Sosialiasi Teknik Pengelolaan Sampah

Brainstorming untuk membuat Sistem Kerja Alir terkait pemanfaatan sampah (Pemilahan, dan proses pengolahannya dengan komposter)

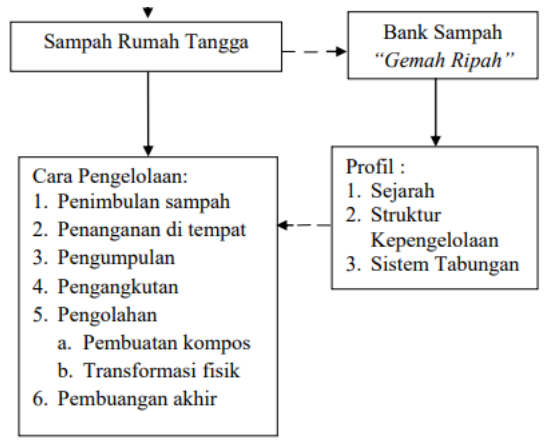

Gambar 4. Flow Proses Pengolahan Sampah Komposter

\section{Simpulan dan saran}

Sampah menjadi salah satu permasalahan besar disetiap negara. Peningkatan jumlah penduduk menyebabkan bertambahnya aktifitas atau kegiatan penduduk setiap harinya. Semua aktifitas akan berdampak pada peningkatan jumlah sampah. Termasuk juga permasalahan sampah di SD Tunas Mandiri. Beberapa permasalahan di SD Tunas Mandiri kurangnya kesadaran masyarakat tentang pengelolaan sampah. Perilaku masyarakat yang membakar sampah dan membuang sampah disungai menjadi kebiasaan sejak dahulu. Selain itu, adanya program dari Pemerintah bersifat top down menyebabkan tidak adanya keberlanjutan program. 
Pemberdayaan Elemen Sekolah dan Komite SD Tunas Mandiri ini membuka wawasan pentingnya belajar pengelolaan sampah yang baik seperti apa serta bisa juga bisa dibuat ladang bisnis yang menjanjikan. Adanya peningkatan dari segi keterampilan dan terbukanya lapangan jasa yang kedepannya dapat menjadi pendapatan lain yang menjanjikan.

\section{Daftar Rujukan}

LPPM Universitas Pembangunan Nasional Veteran Jakarta (UPNVJ) 2017. "Panduan Pelaksanaan Program Penelitian kepada Masyarakat UPN “Veteran” Jakarta.

Pengorganisasian dan Pengembangan Masyarakat, Model dan Strategi Pembangunan berbasis Pemberdayaan. Bandung: Humaniora Isbandi. 2012.

Intervensi Komunitas \& Pengembangan Masyarakat: Sebagai Upaya Pemberdayaan Masyarakat. Jakarta: PT. Raja Grafindo Persada

Suharto, Edi. 2010. CSR \& COMDEV: Investasi Kreatif Perusahaan Di Era Globalisasi. Bandung: Alfabeta

Wibawa, Budhi, Rudi S Darwis, Risna Resnawati dan Sahadi Humaedi. 2013. Panduan Pelaksanaan: Praktikum Pengembangan Masyarakat. Bandung. 